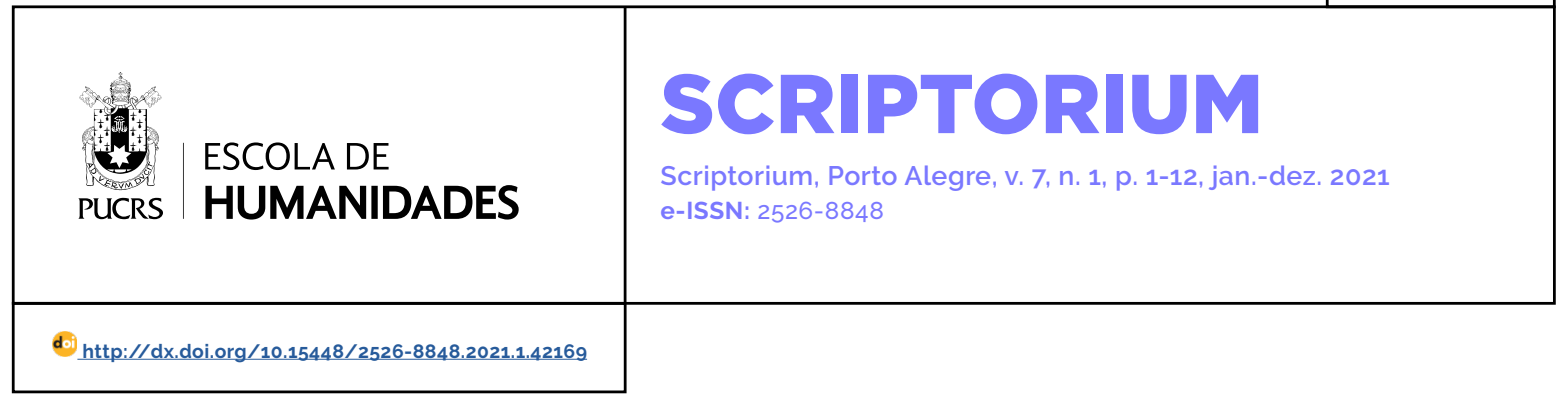

SEÇÃO: TEMATHIS

\title{
Processo de criação como práticas geradas por complexas redes em construção
}

Creative processes as practices generated by complex networks under construction

\author{
Cecilia Almeida Salles ${ }^{1}$ \\ orcid.org/0000-0003-3826-0142 \\ cecilia.salles@gmail.com
}

Recebido em: 10/11/2021

Aprovado em: 12/11/2021

Publicado em: 28/12/2021.
Resumo: O propósito deste artigo é fazer algumas reflexões sobre processos criativos, assumindo-se que devemos partir de uma conceituação de criação. Será apresentado o conceito de criação que sustenta os debates sobre criatividade como conjunto de práticas criativas. A discussão se dá no contexto de pesquisas sobre processos de criação, iniciadas nos anos de 1990 no Grupo de Pesquisa em Processos de Criação (PUC-SP), que discutem os registros dos agentes criativos. Será feito o relato do percurso de construção do conceito de criação como rede em construção. Primeiramente, será apresentada a leitura semiótica da criação como processo sígnico, no contexto do pensamento do filósofo Charles S. Peirce. Em seguida, será discutido o adensamento desta conceituação em diálogo com o conceito de rede de Pierre Musso (2004) e o pensamento da complexidade de Edgar Morin (1998). Ao final. será apresentado o conceito de criação que sustenta a crítica dos processos de criação. Tal conceituação parece ser relevante para a discussão da criatividade e de quaisquer produções, que seriam ações geradas pelas complexas redes aqui abordadas.

Palavras-chave: Processo de criação. Redes da criação. Crítica de processo. Semiótica. Complexidade.

Abstract: The purpose of this article is to make some reflections on creative processes, assuming that we must start from a conceptualization of creation. The concept of creation that sustains debates on creativity as a set of creative practices will be presented. The debate takes place in the context of a research on creative processes, which began in 1990 at the Research Group on Creative Processes (PUC-SP) and discusses the records of creative agents. The construction of the concept of creation as a network under construction will be reported. First, the semiotic interpretation of creation as a sign process will be presented. in the context of the Charles S. Peirce's theory. Then, the development of this conceptualization will be discussed in dialogue with the concept of network by Pierre Musso (2004) and the concept of complexity by Edgar Morin (1998). Finally, the concept of creation that supports the critique of creation processes will be presented. Such conceptualization seems to be relevant for the discussion of creativity and any productions, which would be actions generated by the complex networks addressed here.

Keywords: Creative process. Networks of creation. Process criticism. Semiotics. Complexity

\section{Introdução}

O objetivo deste artigo é fazer algumas reflexões sobre processos criativos, assumindo-se que essas discussões devem partir de uma conceituação de criação. Em outras palavras, abordaremos conceitos de 
criação que sustentam os debates sobre criatividade como conjunto de práticas criativas. Com esse propósito, relataremos o desenvolvimento de uma pesquisa sobre processos criação, junto ao Programa em Comunicação e Semiótica da Pontificia Universidade Católica de São Paulo (COS/PUC-SP), que partiu de um estudo sobre a documentação do escritor brasileiro Ignácio de Loyola Brandão na construção de um de seus romances:2 rascunhos, anotações, diários, relatos sobre músicas ouvidas, fotos, roteiros, mapas, jornais e livros. A pergunta que direcionou a pesquisa foi: o que esse material oferece sobre o processo de criação de Loyola Brandão? Como veremos adiante, essa indagação se expandiu ao longo dos anos e se transformou na busca por uma teoria da criação apoiada na investigação dos arquivos. A observação desses documentos dos processos precisava ser auxiliada por diálogos teóricos para a abordagem e interpretação desse objeto caracterizado pelo movimento e pelo estabelecimento de relação entre diferentes linguagens. Isto é, um enfoque teórico que não conflitasse com essas características tão marcantes do objeto de estudo.

Nesse contexto é que se deu o encontro com a semiótica do filósofo Charles S. Peirce - sendo essa uma teoria que versa sobre o abstrato, fazendo-o de maneira geral e formal, ela oferecia um mapa orientador para a leitura do processo de criação. Destacamos que o conceito geral de signo, seu modo de ação comum a todas as linguagens, foi uma das motivações para a adoção dessa perspectiva teórica, já que oferecia a possibilidade de discutirmos imagens, palavras, sons, gestos etc.; ou seja, a tessitura intersemiótica de tais processos dos registros do escritor.

Ao longo do trabalho, surgiu uma nova questão: as características do processo de criação que encontrávamos em Loyola Brandão seriam exclusivas a ele? Essa pergunta nos motivou a estabelecer nexos entre a documentação produzida pelo escritor com diários, cartas e escritos de outros artistas; metodologia que continuou a ser adotada nas pesquisas subsequentes, evidenciando a recorrência de alguns elementos, bem como o caminho para a uma teoria sobre a criação. Por isso, destacamos outro aspecto importante da generalidade do conceito de semiose, que mais tarde estaria presente na ideia de "redes da criação": 3 possibilidade de discutirmos questões gerais dos processos de criação, propondo uma mediação entre a generalidade da teoria e a especificidade dos artistas estudados. O preenchimento da generalidade com a concretude de um processo signico particular é o esforço no qual se apoiam os estudos dos arquivos, oferecendo uma visão ampla sobre o processo criativo, que age como guia condutor para pesquisas sobre determinadas manifestações artísticas ou sobre artistas especificos. Há questões gerais nos processos, mas o que faz, por exemplo, o cinema ser cinema? Ou, ainda, o que caracteriza o processo de criação de um dado cineasta?

Nessa fase foi construída uma leitura da criação baseada na semiótica de linha peirceana, a qual apresentaremos a seguir - lembrando que a presente discussão dos conceitos semióticos não tem qualquer pretensão de ser definitiva, tampouco a ilusão de esgotar conceitos de extrema complexidade. Nutre, contudo, o propósito de apontar a relevância do conceito de semiose na formulação de uma teorização geral de criação, a partir do estabelecimento de relações entre os diferentes estudos de caso.

\section{Criação como processo semiótico}

O primeiro aspecto a ser destacado, considerando-se a continuidade do signo, é que a criação é processo. Para Peirce, o signo está ligado, inevitavelmente, ao signo que origina; este segundo, por sua vez, gera outro signo e assim por diante, ad infinitum. Essa ausência de autonomia intrinseca ao signo é denominada

\footnotetext{
2 Ver SALLES, Cecilia A. Criação em processo: Ignácio de Loyola Brandão e Não Verás País Nenhum. Tese de doutorado defendida em 1990 junto ao Programa de Linguística Aplicada ao Ensino das Linguagens da PUC-SP.

3 Redes da criação: construção da obra de arte (SALLES, 2006).
} 
sinequismo (PEIRCE, lentre 1931 e 1935], v. 6, §102163) ${ }^{4}$, o princípio de continuidade que determina a permanente evolução do universo sígnico. Evolução, neste caso, significa crescimento em seu sentido mais amplo.

A continuidade é "[...] inseparável da indeterminação e da incerteza" (GAREWICZ, 1978, p. 8). Peirce nos diz que "[...] um signo é objetivamente vago na medida em que, deixando sua interpretação mais ou menos indeterminada, ele reserve para algum outro signo ou experiência possivel a função de completar a indeterminação" (PEIRCE, [entre 1931 e 1935], v. 6, \$102-163). Falemos mais um pouco da indeterminação que caracteriza o signo: "[...] onde quer que subsista o grau ou qualquer outra possibilidade de variação contínua, a precisão continua, a precisão absoluta é impossivel" (PEIRCE, lentre 1931 e 1935], v. 5. §506).

O convívio com uma grande diversidade de documentos de processos nos levou a observar a continuidade da criação materializada nas referências a incansáveis alterações das obras; o que, sob a perspectiva semiótica, gerou a discussão sobre o inacabamento do processo. ${ }^{5}$ A constatação de que a criação é sempre inacabada está estreitamente ligada à conceituação da criação como processo sígnico e, portanto, contínuo que se dirige a todos os objetos de nosso interesse - seja um romance, uma instalação ou um artigo científico - como uma possivel versão daquilo que pode vir a ser modificado. Relativiza-se, assim, a noção de conclusão como uma forma única possivel. Qualquer momento do processo é simultaneamente gerado e gerador (COLAPIETRO, 2014).

Essa ação sígnica contínua é um processo com tendência, ou seja, um processo de causação final (PEIRCE, [entre 1931 e 1935], v. 1, §211), em termos peirceanos. Ransdell (1977) afirma que não há nenhuma dúvida quanto à centralidade do conceito de causação final na teoria de Peirce. Ele acredita que o processo evolutivo, em geral, é uma manifestação da mente. "A mente tem seu modo universal de ação por causação final" (PEIRCE, lentre 1931 e 1935], v. 1, §269). Onde há movimento com propósito, há mente. Tendência carrega o conceito de meta, objetivo e implica luta para obtê-lo. Daí, Peirce definir o propósito como "desejo operativo" (PEIRCE, lentre 1931 e 1935], v. 1, §205).

A causação final é um processo de busca da verdade, que consiste na compulsão decisiva da inteligência investigadora (PEIRCE, lentre $1931 \mathrm{e}$ 1935], v. 2, §333). Ransdell (1979) lembra que no enquadre teórico de Peirce há o abandono da ideia de que exista algo como um critério de verdade. Essa perspectiva, portanto, refuta verdades finais e absolutas enquanto enfatiza a busca.

Como qualquer processo de interpretação sígnica é um processo de causação final, o conceito pode ser usado, segundo Ransdell (1977), tanto nas artes como nas ciências. Peirce (1977, p. 17) diz: "O trabalho do poeta ou novelista não é tão profundamente diferente do trabalho do homem de ciência". Logo, o conceito de causação final tem alguns desdobramentos importantes para a caracterização do processo de criação como semiose, conforme destacamos a seguir.

Peirce afirma que o processo de causação final "[...] sugere um maquinário de eficiência para alcançar o objetivo, que precisa contribuir para o resultado final (PEIRCE, lentre 1931 e 1935], v. 1, §269)". Esse maquinário eficiente seria a causação física ou eficiente para a causação final. Ou seja, para Peirce, ambas não apenas são compatíveis, como também a causação final só pode se realizar pela via da causação eficiente. Logo, a semiose pressupõe uma explicação física em meio às tendências do processo ou "recompensa material" - termos que tomamos de empréstimo de Kandinsky (1990), que descreve o processo de construção de obras como a busca da recompensa material para o poder inventivo e a sensibilidade do artista.

O princípio da continuidade, determinado por sua vagueza intrínseca, nos leva a outra característica da semiose: o falibilismo.

[...] sinequismo ou principio da continuidade é a ideia do falibilismo objetivada. Se falibilismo é a 
teoria de que nosso conhecimento não é nunca absoluto, mas navega num continuum de incerteza e indeterminação, o princípio da continuidade diz que todas as coisas também navegam nesse continuum (Santaella, 1987, p. 196).

Ao mesmo tempo em que processo sígnico pode gerar representações inadequadas da realidade, ele é autocorretivo. Para Peirce, essa propriedade é "uma fantástica característica do raciocínio [...] que tende a se autocorrigir" (PEIRCE, [entre 1931 e 1935], v. 5, \$575).

No entanto, ressalte-se que a correção em termos peirceanos é também dinâmica e não elimia a incidência de erros e acasos. Caminhando na caracterização do processo sígnico, Peirce (1955) destaca ainda que a causação final pode acontecer sem que tenha sido propósito de nenhuma mente. Sua concepção de processo teleológico envolve o reconhecimento da ação do acaso, que age permanentemente, aumentando a variedade do mundo. Trata-se da evolução por variação fortuita, circunstancial, por absolutas indeterminação e espontaneidade. O pensamento criador, em nossa leitura, é alimentado e se desenvolve por meio dessas intervenções, que parecem ter um papel importante na variabilidade do pensamento.

A profusão de registros de momentos dos processos criativos nos quais encontra-se algum tipo de referência a acasos ou a erros pede por uma reflexão mais aprofundada. Muitos estudiosos de processos criativos, adeptos das mais diversas abordagens, discutem esses dois aspectos, na maioria dos casos, de modo independente. Com olhar atento e preocupado em evitar as segmentações, percebemos que deve ser salientada não só a complexidade que envolve cada um desses aspectos, como suas imbricações e entrelaçamentos. À nossa leitura, há o cruzamento dessas duas espécies de interferências (acaso e erro) no fluxo da criação com tendências ou principios direcionadores.

Outra característica do signo estreitamente ligada à continuidade da semiose é seu poder criativo. Como já foi mencionado, "Um signo dá vida a outro signo" (PEIRCE, lentre 1931 e 1935], v. 2. §229). Todo pensamento, por sua vez, é signo, dai podermos dizer que "uma ideia dá origem à outra" (PEIRCE, 1958, v. 7. §356). A natureza auto criativa do universo sígnico está no fato de que todo signo cria, gera, pelo menos, um outro signo. Em outras palavras, o signo se reproduz. Esta é a materialidade - geradora e transformativa - das criações em processo estudadas.

O pensamento detém, assim como signo, natureza inferencial; isto é, toma por certo a existência de algum pensamento prévio. A cognição para Peirce, por definição, está fundada em alguma outra cognição, de forma que inferência e sinequismo são constantes da ordem do signo e do pensamento.

A caracteristica inferencial do processo, por sua vez, nos remete ao raciocínio responsável pela formulação de hipóteses explicativas, a única operação lógica que introduz uma nova ideia. Em termos peirceanos falamos de abdução, que se trata de um dos modos de desenvolvimento do pensamento. Como afirma Peirce, "[...] abdução ou a sugestão para uma teoria explicativa é inferência" (1903). O aspecto inferencial da abdução nos mostra que os diferentes elementos da hipótese estavam em nossa mente antes. O que lampeja é a ideia de juntar elementos - pensamentos e/ou materialidades - que ainda não tínhamos unido, o que surge diante de nossa contemplação como uma nova sugestão.

A abdução, como uma das formas de desenvolvimento do pensamento, é de extrema relevância para o conceito de criação aqui apresentado, pois nos afasta da visão baseada em insights sem história.

A abdução é uma formulação frágil, ou seja, um ato de inferência que adota uma hipótese em estado experimental (Hume on Miracles', PEIRCE, lentre 1931 e 1935], v. 6, \$525) a ser testada. É o método de formar uma previsão geral sem nenhuma certeza de que será bem-sucedida, podendo, ao longo do processo de testagem, se provar errada. É um ato de insight arraigado em hipóteses prévias e extremamente falivel (PEIRCE, lentre 1931 e 1935], v. 5, §181).

O conceito de continuidade do signo, relacionado a seu caráter criativo e mediado, acarreta outra consequência discutida por Garewicz (1978) 
e relevante para as reflexões sobre a criação. Um signo isolado não tem sentido, como já foi discutido. "É um erro fundamental supor que uma ideia isolada pode ser qualquer outra coisa do que totalmente cega" (PEIRCE, lentre 1931 e 1935], v. 4. §711). Como desdobramento desta questão, Garewicz aponta que

[...] nenhuma parte da cognição é mais valiosa do que outras. Sinequismo rejeita a diferenciação entre certos insights diretos e conhecimento mediado e falivel. Toda cognição é feita da mesma matéria-prima, isto é, feita de signo. Desse modo, toda cognição é também do mesmo valor cognitivo. Continuidade significa, sob essa perspectiva, uniformidade de valor cognitivo. Todos os signos têm o mesmo valor de cognição mediada (1978, p. 13).

Com a citação acima, ressaltamos a necessidade do estabelecimento de relação entre os diferentes dados oferecidos pelos documentos da criação e da constatação de ausência de hierarquia entre eles.

Por fim, destacamos que continuidade significa também a destruição dos mitos do signo originário e do último absoluto. Estando o signo em progressão e regressão infinitas, destrói-se o ideal de um começo e de um fim definitivos. Estamos sempre no meio da cadeia semiótica; embora seja sempre possivel identificar um ponto no processo contínuo como sendo mais próximo do ponto de partida, todo estado de parada na cadeia é, também, um novo ponto de partida. Trata-se da noção de semiose enquanto cadeia infinita de signos, dentro da qual a relação do signo com o objeto recai numa regressão infinita de signos e a relação do signo com o interpretante entra em uma progressão infinita de signos. Esses conceitos peirceanos foram extremamente relevantes na conceituação de criação como processo ou semiose, apresentada neste artigo.

Ao estabelecermos nexo entre as reflexões de artistas diversos e a conceituação de semiose e alguns de seus desdobramentos teóricos, poderiamos definir o processo de criação como trabalho sensivel e intelectual de construção de objetos artísticos, científicos e mediáticos. Sob esta perspectiva, referimo-nos à coexistência dinâmica das três categorias da Fenomenologia de Peirce: primeiridade (sentimento, sensação), secundidade (ação, confronto) e teceiridade (interpretação, sintese intelectual).

Ampliando a definição com a utilização dos conceitos até aqui apresentados, esse percurso sensivel e intelectual pode ser descrito como um movimento falivel com tendências, sustentado pela lógica da incerteza, englobando a intervenção do acaso e abrindo espaço para a introdução de ideias novas. Um processo no qual a regressão e a progressão são infinitas, portanto, sem definição de ponto inicial, nem final. Foge-se, assim, da busca pela origem da obra e relativiza-se a sua conclusão. Cada versão contém, potencialmente, um objeto acabado; o objeto considerado final representa, de forma também potencial, apenas um dos momentos do processo.

Os artistas caem, por vezes, na tentação da busca pelo ponto de partida daquela obra, ao afirmarem que o romance, por exemplo, nasceu de um conto, mas também de uma cena vivida, de um texto lido etc. Do mesmo modo, o artista se vê diante da impossibilidade de determinar o ponto final absoluto, o final de um processo ou momento que o agrada o suficiente para poder mostrar publicamente (um ponto final suportável). Ele pode já estar entrando em um novo processo que, de algum modo, mantém diálogo com o processo anterior, ou pode, ainda, retomar essa obra em outros momentos das mais variadas maneiras.

O conceito criação como processo semiótico sustenta o livro O Gesto Inacabado: processo de criação artística (SALLES, 2011) que se propõe a discutir a criação em uma abordagem processual, mas vai, provavelmente, além dos limites desse objeto especifico. Com ele, oferecemos instrumentos para uma teorização que se ocupa dos fenômenos em sua mobilidade. Acreditamos que essas discussões se tornaram fundamentais para pensarmos certas questões contemporâneas, que envolvem, por exemplo, a ideia de autoria, a exploração de arquivos e a intrincada relação obra e processo.

Essas novas questões pareciam merecer maior atenção e exigir a ampliação da leitura dos processos de criação em contribuições teóricas que dessem conta de múltiplas conexões em permanente 
mobilidade, gerando uma expansão dos diálogos teóricos. Chegamos, assim, ao conceito de rede de Pierre Musso (2004) no contexto do pensamento da complexidade de Edgar Morin (2011).

\section{Novos diálogos teóricos}

A proposta central do livro Redes da Criação: construção da obra de arte (SALLES, 2006) parte da necessidade de pensar a criação como rede de conexões, cuja densidade está estreitamente ligada à multiplicidade das relações que a mantêm. No caso do processo de construção de uma obra, podemos falar que, ao longo desse percurso, a rede ganha complexidade quando novas relações vão sendo estabelecidas.

Pierre Musso (2004), ao discutir a ideia das redes, diz se preocupar com a explosão desse conceito que, de certo modo, o supervaloriza em metáforas. Com a mesma preocupação, também levamos adiante essa perspectiva, por acreditarmos que seja necessária para a compreensão da plasticidade do pensamento em criação, que se dá justamente nesse seu potencial de estabelecer nexos. Essa abordagem do processo criativo talvez seja responsável pela viabilização de leituras não lineares e libertas das dicotomias, tais como: intelectual e sensivel; externo e interno; autoria e não autoria; acabado e inacabado; objetivo e subjetivo; e movimento prospectivo e retrospectivo.

Como afirma André Parente (2004, p. 9), a noção de rede vem despertando um tal interesse nos trabalhos teóricos e práticos, em campos tão diversos - como a ciência, a tecnologia e a arte - que temos a impressão de estar diante de um novo paradigma, ligado a um pensamento das relações, em oposição a um pensamento das essências. Em nossos estudos dos processos de criação, incorporamos o conceito de redes por acreditarmos que seja indispensável uma abordagem relacional para discutirmos algumas caracteristicas observadas nas práticas artísticas: simultaneidade de ações, ausência de hierarquia, não linearidade e intenso estabelecimento de nexos. Este conceito reforça a conectividade e a proliferação de conexões, associadas ao desenvolvimento do pensamento em criação e ao modo como os artistas se relacionam com seu entorno.

A criação artistica é marcada, como vimos, por seu movimento e dinamicidade que nos põem em contato com um ambiente que se caracteriza pela flexibilidade, não fixidez, mobilidade e plasticidade. Recorremos, propositalmente, a aparentes sinônimos para conseguirmos nos transportar para esse ambiente dos processos de criação dos inúmeros e infindáveis cortes, substituições, adições ou deslocamentos. Isso nos leva, por exemplo, a diferentes possibilidades de obra apresentadas nas séries de rascunhos, tratamentos de roteiros, esboços etc.; propostas de obras que se modificam ao longo do processo; partes de uma obra que reaparecem em outros trabalhos do próprio artista; ainda, fatos lembrados ou livros lidos sendo levados para obras em construção, em referências diretas ou indiretas. Identificamos, também, uma memória criadora em ação e que se apresenta nessa perspectiva da mobilidade e da transformação: não como um local de armazenamento de informações, mas um processo dinâmico que se modifica com o tempo. Novas percepções sensiveis, decorrentes de um olhar que não conhece fixidez, impõem modificações e novas conexões.

Esse percurso contínuo em permanente mobilidade nos leva, de volta, ao conceito de inacabamento intrinseco a todos os processos. Tomando a continuidade e a incompletude como aspectos que the são inerentes, há sempre uma diferença entre aquilo que se concretiza e o projeto do artista que está por ser realizado. Nesse sentido, não é possivel falarmos do encontro de obras acabadas, completas, perfeitas ou ideais. A busca, no fluxo da continuidade, é sempre incompleta e o próprio projeto que envolve a produção das obras, em sua variação contínua, muda ao longo do tempo. o que move essa busca talvez seja o desejo do encontro da obra que satisfaça plenamente.

O objeto que está sendo criado, se tomado nessa visão temporal, é mutável; construir esse objeto que permanentemente flui no tempo implica algo que tende a escapar aos domínios do próprio criador. Transitoriedade acarreta inacessibilidade (COLAPIETRO, 2016), de forma que a relação en- 
tre o que se tem e o que se quer reverter-se em contínuos gestos aproximativos - adequações que buscam a sempre inatingivel completude. O artista lida com sua obra em estado de contínuo inacabamento, o que é experienciado como insatisfação. No entanto, a incompletude traz, também, seu valor dinâmico, na medida em que gera busca que se materializa nesse processo aproximativo, na construção de uma obra específica e na criação de outras obras, mais outras e outras ainda. O objeto dito acabado pertence a um processo que segue inacabado, o que não implica em desvalorização da obra entregue ao público, mas na dessacralização desta como final, forma-prima e única possivel.

Essas afirmações baseiam-se nos dados oferecidos pelos próprios artistas, como versões diversas de um livro em edições diferentes, filmes com mais de uma montagem, citações clássicas como a de Carlyle, sempre lembrada por Borges, que diz que "[...] publicamos para não passar a vida corrigindo" (BORGES, 1984). Há ainda histórias como aquela atribuida a Bonnard que, quando já era um pintor famoso, entrava escondido nos museus, com pincéis e tintas, para, quando os guardas não estavam olhando, retocar os próprios quadros. Ao mesmo tempo, acompanhar o processo de um artista nos permite - ou, melhor, nos obriga - a enfrentar documentos privados que mostram um objeto literário, por exemplo, recebendo ajustes dia após dia, mesmo depois de entregue ao editor. Há também inúmeras anotações que registram o ponto final do romance, seguidas de novos apontamentos, falando de problemas ou insatisfações em relação ao texto que geram, por sua vez, modificações.

Nesse contexto, indagamos: o que nos dá a certeza de que se o livro fosse entregue, digamos, um mês depois, ele não teria alterações e seria diferente daquele que está nas livrarias? Assim como Morin (2000, p. 39) afirma que na ciência uma teoria tem sempre incerteza de seus resultados, ainda que possa fundar-se em dados exatos, o artista também enfrenta um processo que não permite previsão e predição; em outras palavras, ele opera no universo da incerteza, da mutabilidade, da imprecisão e do inacabamento.

A incompletude do processo destaca ainda a sobrevivência de qualquer elemento a partir da inter-relação com outros. Observamos que uma anotação se completa em outra - prévia ou vindoura - ou em uma fala de um personagem; um problema no desenvolvimento da obra se completa em leituras ou conversas com amigos etc. Essa visão do processo de criação nos coloca em pleno campo relacional, sem vocação para o isolamento de seus componentes, o que exige do pesquisador permanente atenção a contextualizações e ativação das relações que o mantém como sistema complexo. Discutiremos essas questões com mais vagar, a seguir, ao apresentarmos o conceito de rede.

O estado de dinamicidade organiza-se na confluência de tendências e acasos, tendências essas que direcionam, de algum modo, as ações em meio a esse universo de vagueza e imprecisão. São rumos vagos que, tais como condutores maleáveis, orientam o processo de construção das obras. O movimento dialético entre rumo e incerteza gera trabalho, que se caracteriza como uma busca de algo que está por ser descoberto - uma aventura em direção ao vagamente conhecido. Ao mesmo tempo, o desenvolvimento do processo vai levando a determinadas tomadas de decisão, que propiciam a formação de linhas de força, caminhos promissores que atraem a atenção exploratória do autor. Esses princípios direcionadores passam a sustentar as obras em construção e balizam, de algum modo, as avaliações e escolhas do artista.

Nesse percurso, tendências se cruzam com o acidental, causando possiveis modificações de rumo. Essa intervenção do acaso é observada nos relatos dos artistas sobre imprevistos externos e internos ao processo. Estes são enfrentados de diferentes maneiras e recebem tratamentos diversos, podendo ser responsáveis por interessantes descobertas. Aceitar a intervenção do imprevisto implica compreender que o artista poderia ter feito aquela obra de modo diferente daquele que fez; ao assumirmos que há concretizações alternativas, admitimos que outras obras teriam 
sido produzidas. Chegamos, desse modo, à possibilidade de que haja mais de uma forma que satisfaça as tendências de um processo e seja mostrada publicamente.

Retomando a dinamicidade e a incerteza do percurso criador, não há garantia de que as alterações levem sempre à melhora dos objetos em construção. Daí as idas e vindas, retomadas, adequações, possibilidades de obra aguardando novas avaliações, reaproveitamentos e novas rejeições. Alguns dos documentos dos processos com os quais lidamos são testemunhas dessa caracteristica da criação: são guardados rascunhos, anotações ou esboços, ou seja, tentativas de obras que podem um dia vir a ser recuperadas. Os atos de rejeitar, adequar ou reaproveitar são permeados por critérios que nos interessa conhecer, visto que refletem modos de desenvolvimento de pensamento, nos instigando a compreender, descrever e nomear. Diante dessas ações múltiplas e diversas, fica bastante claro que lidamos com o tempo da criação artística em uma perspectiva não linear.

Essa não linearidade nos leva ao conceito de rede, embora este abarque muitas outras questões. Pierre Musso (2004) fala das redes como um novo paradigma, ligado a um pensamento das relações. Para nosso interesse específico, muito nos atrai a associação de rede a um modo de pensamento. Explicando de maneira especular: precisamos construir uma rede para falarmos de uma rede em construção. É interessante destacar que essas reflexões que estamos desenvolvendo têm esse conceito de rede como norteador, em mão dupla. Queremos ressaltar que, por um lado, todos os pesquisadores que se interessam pela compreensão dos processos de criação estão falando de uma rede que se constrói e esses pensadores da criação, por sua vez, necessitam de uma abordagem que esteja também inserida nesse paradigma relacional. Ou seja, o modo de apreensão de um pensamento em rede só pode se dar também em rede. Dai retomarmos, em muitos momentos, conceitos e citações que precisam ser revistos em novos contextos para que possam gerar outras conexões.
Musso (2004, p. 31) propõe uma definição de rede que, embora faça permanente referência a "estruturas" (as quais nos parecem ser muito mais associáveis a paradigmas de sistemas fechados), nos oferece várias portas de entrada proficuas para esse debate. Vamos aos aspectos ressaltados pelo autor que nos auxiliarão a caracterizar as redes da criação.

Musso fala em elementos de interação, interconexão instável no tempo e variabilidade de acordo com regras de funcionamento. Os elementos de interação são os picos ou nós da rede, ligados entre si: um conjunto instável e definido em um espaço de três dimensões. Morin (2002b, p. 72), em outro contexto teórico, descreve interações como ações reciprocas que modificam o comportamento ou a natureza dos elementos envolvidos; supõem condições de encontro, agitação, turbulência e tornam-se, em certas condições, inter-relações, associações, combinações, comunicações etc:; ou seja, dão origem a fenômenos de organização. Morin fala também em jogo de interações, cujas regras podem parecer como as leis da natureza. Há algo nas propriedades associadas à interatividade, em ambas as definições, que consideramos importante para compreendermos as conexões da rede da criação: influência mútua, algo agindo sobre outra coisa e algo sendo afetado por outros elementos.

Ao adotarmos o paradigma da rede estamos pensando o ambiente das interações, dos laços, da interconectividade, dos nexos e das relações, que se opõem claramente àquele apoiado em segmentações e disjunções. Estamos, assim, em plena tentativa de lidar com a complexidade e as consequências do enfrentamento desse desafio. "Por que estamos desarmados perante a complexidade?", pergunta-se Morin (2002a, p. 11). Ele mesmo responde:

[...] porque nossa educação nos ensinou a separar e isolar as coisas. Separamos seus objetos de seus contextos, separamos a realidade em disciplinas compartimentadas umas das outras. A realidade, no entanto, é feita de laços e interações, e nosso conhecimento é incapaz de perceber o complexus - aquilo que é tecido em conjunto (2002a, p. 11). 
Temos, segundo Morin, um velho paradigma que nos obriga a disjuntar, a simplificar, a reduzir sem poder conceber a complexidade; buscamos outro capaz de reunir, de contextualizar, de globalizar, mas, ao mesmo tempo, capaz de reconhecer o singular, o individual, o concreto. Assim como ecologistas que estudam as interações formando sistemas (MORIN, 2000), estamos preocupados com as interações, tanto internas quanto externas aos processos de criação, pois estes são sistemas abertos que interagem também com o meio ambiente. Coloca-se em crise o conhecimento do objeto fechado, estático e isolado.

O pensamento em criação manifesta-se, em muitos momentos, nesse intenso campo de interações. Uma conversa com um amigo, uma leitura, um objeto encontrado ou até mesmo um novo olhar para a obra em construção - essas experiências de interação trazem consigo o potencial de novas possibilidades que se apresentam, podendo ou não ser levadas adiante. As interações são muitas vezes responsáveis por essa proliferação de novos caminhos: provocam uma espécie de pausa no fluxo da continuidade, um olhar retroativo e de avaliação, o que, por sua vez, gera uma rede de possibilidades de desenvolvimento da obra. Essas possibilidades levam a seleções e ao consequente estabelecimento de critérios.

A interatividade é, portanto, uma das propriedades indispensáveis da rede para falarmos dos modos de desenvolvimento de um pensamento em criação, ou seja, localizado no campo relacional. Voltamos ao aspecto inferencial dos processos de criação, que nos leva a observar que toda ação está relacionada a outras ações de igual relevância e, ao mesmo tempo, nos remete à formulação de hipóteses (abdução peirceana) essas últimas responsáveis pela entrada de ideias novas a partir da consideração de questões que, de algum modo, já eram conhecidas. O destaque está na visão evolutiva do pensamento que enfatiza as relações entre elementos já existentes. Se o pensamento é relacional, há sempre signos prévios e futuros. Esta abordagem do movimento criador que o coloca como uma complexa rede de inferências reforça a contraposição à visão da criação como uma inexplicável revelação, ou uma epifania sem história, como vimos anteriormente.

Refletir sobre interações, pensamento inferencial e estabelecimento de relações leva-nos a pensar a criação artística no campo da complexidade, rompendo o isolamento dos objetos ou sistemas, impedindo sua descontextualização e ativando as relações que os mantêm como sistemas complexos. Morin (2000, p. 207) aponta os problemas acarretados pela especialização abstrata:

[...] extrai um objeto de seu contexto e do seu conjunto, rejeita os laços e as intercomunicações com seu meio e o insere num compartimento, que é aquele da disciplina cujas fronteiras destroem arbitrariamente a sistematicidade (a relação de uma parte com o todo) e a multidimensionalidade dos fenômenos.

Esse pensamento, segundo o autor, revela a inanidade do reducionismo que dissolve os sistemas para considerar somente suas partes, do atomismo que concebe seus objetos de maneira isolada, e produz o restabelecimento dos conjuntos constituídos a partir de interações, retroações, inter-retroações constitutivas do tecido complexo.

Uma decisão do artista tomada em determinado momento tem relação com outras anteriores e posteriores. Do mesmo modo, a obra vai se desenvolvendo por meio de uma série de associações ou estabelecimento de relações. Muitas vezes, a "anotação no guardanapo do bar" não é nada mais do que a tentativa de não deixar uma associação se perder. Os novos diálogos teóricos possibilitaram uma conceituação de processo de criação mais complexa, que sustenta nossas reflexões sobre criatividade.

\section{Processo de criação como rede em construção}

Essa conceituação de criação baseia-se nas contribuições de Pierre Musso (2004) sobre as redes; já o termo "em construção" foi a forma encontrada para acoplar o conceito de criação como processo sígnico, acima apresentado, ao conceito de rede. 
Trata-se de um percurso de ação (construção/conflito/confronto/encontro) sensivel e intelectual, sofrendo intervenções do consciente e inconsciente. ${ }^{6}$ Afasta-se, assim, da dicotomia intelectual ou sensivel, que ainda rege as discussões de muitos pensadores da criação, os quais separam, por exemplo, o processo da ciência como objetivo e intelectual, enquanto o da arte seria subjetivo e sensivel. Nossa proposta tem a premissa de que todos os processos comportam esses três aspectos.

A criação como rede pode ser descrita como um processo contínuo de interconexões, com tendências vagas, gerando nós de interação, cuja variabilidade obedece a principios direcionadores. Esse processo contínuo, sem ponto inicial nem final, é um movimento falivel, sustentado pela lógica da incerteza; engloba a intervenção do acaso e abre espaço para a introdução de ideias novas.

As interconexões nos colocam no campo relacional: toda ação está ligada a outras ações de igual relevância, sendo assim um percurso não linear e sem hierarquias. A construção de uma rede, ou seja, sua transição de uma rede simples para outra mais complexa, é consubstancial a sua definição. As interconexões geram os picos ou nós da rede, elementos de interação ligados entre si, que se manifestam como os eixos direcionadores de nossas pesquisas.

As tendências são rumos vagos que orientam o processo de construção dos objetos, no ambiente de incerteza e imprecisão; geram trabalho em busca de algo que está por ser descoberto. Elas podem ser observadas sob duas perspectivas: constituição de projetos poéticos ou princípios direcionadores e práticas comunicativas.

A procura por recompensa material, ou seja, o percurso de construção da rede entrelaçado ao embate com materialidades diversas, é igualmente dinâmica e está inserida no espaço e tempo da criação, o que inevitavelmente afetam o realizador ou agente criativo. Ao longo do processo que confere fisicalidade ao pensamento inferencial, vão sendo estipuladas restrições ou delimitações de naturezas diversas; são elas que tornam a construção da obra possivel. O desenvolvimento do processo leva a decisões que propiciam a formação de alguns principios direcionadores, dando consistência aos objetos em construção.

O conceito de tendência advém da definição de semiose, ou movimento sígnico em termos peirceanos, como discutido anteriormente neste artigo. Lembremos que, segundo o autor, todo processo sígnico carrega o conceito de meta, de objetivo, e implica luta para obtê-lo.

As tendências dos processos foram observadas sob dois pontos de vista: construção do projeto poético e das práticas comunicativas. Ambos são desdobramentos do conceito de semiose, que foi por meio deles transposto ao contexto da criação; são, portanto, imbuidos da mesma natureza geral. O modo de ação da tendência é transportado para a constituição do projeto poético e as práticas comunicativas.

O desenvolvimento da pesquisa levou-nos a reforçar certos aspectos, a adicionar novos e a rever outros. O uso do termo poético para designar a natureza do projeto que rege os processos de criação é um caso dessas adequações necessárias, diante da resistência contra o uso de "poético" para algumas áreas da produção. No momento em que fizemos a opção de manter o emprego do termo, tentávamos com ele englobar os aspectos éticos e estéticos (Peirce) das tendências. No entanto, percebemos não haver qualquer limitação que nos restringisse ao uso de uma só palavra para designar todos os tipos de projeto. O projeto pode, assim, adquirir uma grande diversidade de especificações, sem afetar seu conceito e sua função lógica no âmbito da criação como rede: podemos falar de projeto artístico, projeto cinematográfico, projeto teatral, projeto jornalístico, projeto de pesquisa etc. $O$ importante é que os termos levem consigo a mesma carga teórica que evoca o modo de ação das tendências.

Em meio às tendências vagas encontra-se o projeto do artista, tecido complexo entrelaçado

\footnotetext{
6 Ver discussão mais aprofundada em. SALLES, Cecilia A. Processos de criação em grupo: diálogos. São Paulo: Estação das Letras e Cores, 2017.
} 
por principios direcionadores, de natureza ética e estética, presentes nas práticas criadoras, relacionados à produção de uma obra específica e que também atam o projeto daquele criador. Esses princípios são as teorias implícitas no fazer, relativas à singularidade do artista; aglutinam planos de valores, formas de representar o mundo, gostos e crenças que regem o seu modo de ação. São, contudo, princípios dinâmicos e que se transformam ao longo da busca contínua. Logo, o próprio projeto, que direciona de algum modo a produção das obras, muda ao longo do tempo.

Interações geram campos de possibilidade; daí a relevância de compreender as implicações das escolhas, tomadas de decisão e critérios para, consequentemente, identificarmos alguns dos comandos que visam tornar possiveis as obras.

Já as reflexões sobre as tendências dos processos, sob o ponto de vista das práticas comunicativas, dialogam com a oportuna constatação de Mário de Andrade (1989, p. 61): "[...] a arte é social porque toda obra de arte é um fenômeno de relação entre seres humanos". O processo de criação mostra-se, também, como uma tendência para outros, na medida em que está inserido nas complexas redes culturais: o projeto de cada artista insere-se na frisa do tempo da arte, da ciência e da sociedade em geral.

$\mathrm{O}$ aspecto comunicativo das tendências dos processos nos leva à leitura particular da teoria peirceana efetuada por Colapietro (2014): o sujeito como agente comunicativo, assumindo a forma de comunidade. O sujeito como falante não é nunca só falante em qualquer elocução, há ecos do discurso de outros, o que nos faz entendê-lo como fonte de pensamento e ação, sentimentos e sonhos. Esses sujeitos-comunidades travam, ao longo dos processos de criação, uma grande diversidade de diálogos de natureza inter e intrapessoais com a obra em processo, com futuros interlocutores, com a crítica e com os membros dos grupos onde atuam.

Os percursos de construção das redes (recompensa material) envolvem essa complexa inserção nas redes culturais, nas quais estão imbricados outros tantos elementos como a memória, a percepção, os procedimentos de criação, as mediações e os modos de desenvolvimento do pensamento (processos cognitivos). Essas reflexões, no entanto, não fazem parte do escopo desta publicação. ${ }^{7}$

Terminando o relato da pesquisa que gerou o desenvolvimento de uma teorização sobre processos de criação baseada no conceito-chave de criação como rede em construção, voltamos ao ponto de partida, agora municiados dos anteparos teóricos: acreditamos que os estudos acerca da criação são essenciais para a discussão da criatividade e de quaisquer produções - estas seriam práticas ou ações geradas pelas complexas redes aqui abordadas.

\section{Referências}

ANDRADE, Mário de. O banquete. São Paulo: Livraria Duas Cidades, 1989.

BORGES, Jorge L. Conversaciones con Borges. Buenos Aires: Atlantida, 1984.

COLAPIETRO, Vincent M. Peirce e a abordagem do self: uma perspectiva semiótica sobre a subjetividade humana. São Paulo: Intermeios, 2014

COLAPIETRO, Vincent M. Os locais de criatividade sujeitos fissurados, práticas entrelaçadas. In: PINHEIRO, Amálio.; SALLES, Cecília A. (org.). Jornalismo expandido: práticas, sujeitos e relatos entrelaçados. São Paulo: Intermeios, 2016. p. 43-61.

GAREWICZ, Hanna B. Sign and Continuity. Ars: Semiotic Internacional Journal of American Semiotic, USA, 1978.

JOHANSEN, Jorgen D. Prolegomena to a semiotic theory of text interpretation. In: Semiotica, La Haya, v. 57. n. 3-4, 1985

JOHANSEN, Jorgen D. The place of semiotics in the study of literature'. In: OLIVEIRA, Ana Claudia; SANTAELLA, Lúcia (org.). Semiótica e literatura: cadernos PUC 28. São Paulo: EduC, 1987.

KANDINSKY, Wassily. Do espiritual na arte. São Paulo Martins Fontes, 1990.

MORIN, Edgar. A inteligência da complexidade. São Paulo: Petrópolis, 2000.

MORIN, Edgar. Complexidade e ética da solidariedade. In: CASTRO, Gustavo; CARVALHO, Edgar de Assis; ALMEIDA, Maria da Conceição (org.). Ensaios de complexidade. Porto Alegre: Sulina, 2002a. p. 11-20. 
MORIN, Edgar. O Método 1: a natureza da natureza. Tradução de llana Heineberg. Porto Alegre: Sulina, 2002b.

MORIN, Edgar. O Método 4: as ideias. Habitat, vida, costumes, organização. Tradução de Juremir Machado da Silva. Porto Alegre: Sulina, 2011.

MUSSO, Pierre. A filosofia da rede. In: PARENTE, André (org.). Tramas da rede. Porto Alegre: Sulina, 2004.

PARENTE, André. Enredando o pensamento: redes de transformação e subjetividade. In: PARENTE, André (org.). Tramas da rede. Porto Alegre: Sulina, 2004. p. 91-110.

PEIRCE, Charles S. Philosophical writings. New York: Dover Publication Inc., 1955.

PEIRCE, Charles S. Semiótica. São Paulo: Perspectiva, 1977.

PEIRCE, Charles S. Collected papers. Editado por Charles Hartshorne e Paul Weiss. USA, Harvard Press lentre 1931 e 1935]. v. 1-6.

PEIRCE, Charles S. Collected papers. Editado por Arthur W. Burks. Cambridge: Harvard Press, 1958. v. 7-8.

RANSDELL, Joseph. Some leading ideas of Peirce's semiotic. In: Semiotica, La Haye, v. 19, n. 3-4, p.157-178, 1977.

RANSDELL, Joseph. Semiotic objectivity. In: Semiotica, La Haye, v. 26, n. 3-4, p. 261-288, 1979.

RANSDELL, Joseph. Deduction [1903]. In: Bergman, Mats.; Paavola, Sami. (org.). The Commens Dictionary: Peirce's Terms in His Own Words. [2014]. Disponivel em: http://www.commens.org/dictionary/entry/quote-harvard-lectures-pragmatism-lecture-v-deleted-passage-1. Acesso em: 16 jul. 2021.

SALLES, Cecilia A. Gesto Inacabado: processo de criação artística. 5. ed. São Paulo: Intermeios. 2011.

SALLES, Cecilia A. Redes da criação: construção da obra de arte. Vinhedo: Ed. Horizonte, 2006.

SALLES, Cecilia A. Processos de criação em grupo: diálogos. São Paulo: Estação das Letras e Cores, 2017.

SANTAELLA, Lucia. Semiótica e outras ciências. In: OLIVEIRA, A. C.; SANTAELLA, L. (org.). Semiótica da comunicação e outras ciências: cadernos PUC 30. São Paulo: EDUC, 1987.

\section{Cecilia Almeida Salles}

Doutora em Linguística Aplicada e Estudos de Línguas pela Pontifícia Universidade Católica de São Paulo (PUC-SP), em São Paulo, SP, Brasil. Professora titular dos Programa de Pós-Graduação em Comunicação e Semiótica e de Literatura e Critica Literária da Pontifícia Universidade de São Paulo (PUC-SP), em São Paulo, SP, Brasil.

\section{Endereço para correspondência}

\section{Cecilia Almeida Salles}

Pontifícia Universidade Católica de São Paulo

Alameda Ministro Rocha Azevedo, 373, apto. 42a 01410-001

São Paulo, SP, Brasil

Os textos deste artigo foram revisados pela Poá Comunicação e submetidos para validação da autora antes da publicação. 